\title{
Energy-Environment Resolution
}

WHEREAS the countries of the world are striving to improve their living standards, and thus-in addition to adopting all appropriate conservatioin measures-must increase their energy consumptions in the long run,

WHEREAS the main energy sources at present are fossil fuels,

WHEREAS fossil fuels are finite in amount and will eventually be depleted, with the downturn in production expected to start early in the next century, if not before,

WHEREAS it is prudent to plan and begin conversion to the next energy-system by making use of the remaining fossil-fuel sources (and also other conventional energy sources, such as nuclear, etc.) to achieve a smooth changeover, which is expected to take half-a-century or so,

WHEREAS it is also prudent to preserve the diminishing stocks of the fossil fuels for non-fuel applications (such as lubricants, synthetic fibers, plastics, and fertilizers), for which there may be no substitutes,

WHEREAS the combustion products of fossil fuels are causing growing damage to our Biosphere (the only domain in the Universe that is known to be supportive of life) and especially to its living components through pollution, acidic precipitation, $\mathrm{CO}_{2}$, and carcinogens,

WHEREAS the combustion products and their harmful effects do not stop at the national boundaries,

WHEREAS it is of the utmost importance to keep The Biosphere clean and fit for life, and hence the energy sources and energy carriers as clean as possible,

WHEREAS there exist 'clean' primary energy sources,

WHEREAS there is a need for two types of energy carriers, namely, electricity (meeting about one-quarter of the demand at the consumer end) and fuel (meeting about threequarters of the demand),

WHEREAS there exists technology for the production and utilization of the environmentally most compatible and most efficient fuel-energy carrier, namely hydrogen,

WHEREAS there is a necessity for a self-regulating system, to ensure that Man-induced factors (energy or otherwise) do not harm The Biosphere or threaten life,
IT IS HEREBy ReSOLVED:

THAT products (energy carriers and otherwise) be made responsible for the harm they cause to The Biosphere and to life, directly or through their waste or their manufacture,

THAT the price of each product include an 'environmental surcharge' to cover its environmental damage,

THAT the environmental surcharge be used by appropriate authorities to undo such damage to The Biosphere, life, and Made-made structures; to cover related medical, restoration, and relief, expenses; and to compensate the victims,

THAT there must be international cooperation to ensure equitable and uniform application of the environmental surcharge.

ImPlementation of the Above Will Result in the following lasting and universal benefits:

ENSURE that eventually the present fossil-fuel system would be replaced by a clean and environmentally compatible energy system, the hydrogen energy system,

ENSURE that energy (fossil, nuclear, etc.) would be available for the change-over, thus resulting in a smooth change with no upheavals,

ENSURE that some supplies of fossil fuels would be preserved for non-fuel applications, for which there might be no substitutes,

PROMOTE world-wide economic development and hence international harmony as progressively less unproductive work would be required to undo the environmental damage; and, through the utilization of an efficient and renewable energy carrier,

SAVE The Biosphere and life from conceivable extinction by ensuring that products, their wastes, and manufacturing methods, would be environmentally compatible.

[Communicated by]
T. NEJAT VEZIROGLU, Director
Clean Energy Research Institute
University of Miami
Coral Gables
Florida 33134, USA.

[Communicated by] T. Nejat Veziroglu, Director University of Miami Florida 33134, USA.

\section{European Protected Areas Diploma's Twentieth Anniversary}

The European Diploma, now 20 years old, can be awarded at a government's request to natural areas, sites, or features, which are of international value and particularly of European interest from the point of view of protection of the natural heritage-by virtue of their scientific, cultural, aesthetic, and/or recreational, quality, and which are protected. The European Diploma places the site or feature under the sponsorship of the Council of Europe.

The first three diplomas were awarded in 1966 to the Nature reserves of Hautes-Fagnes in Belgium and of $\mathrm{Ca}-$ margue in France, and to the Peak District National Park in the United Kingdom. The Diploma is awarded for a period of five years, following an on-the-spot appraisal. It may be renewed after appraisal every five years, provided that the situation in the area is the same as when the award was made, and there has been no deterioration. An annual report on the situation of, and improvements to, the area has to be submitted to the Council of Europe. If a site is seriously endangered, the Diploma may be withdrawn.

The Committee of Experts on Protected Areas recently met in Strasbourg to consider the annual reports on the 21 areas currently holding the Diploma. It proposed that the Diploma be awarded to the Bayerischer Wald National Park (Federal Republic of Germany), in Category A, pro- vided certain conditions are met-including a gradual reduction in logging of the order of $50 \%$ and a proportionate increase in the size of the reserves.

Areas holding the Diploma are under constantly increasing pressures which endanger their priority objectives of ecosystem conservation. The renewal of the Diplomas awarded to seven Nature reserves and national parks was accompanied by certain recommendations and conditions as follows:

The Hautes-Fagnes Nature Reserve (Belgium) should draw up a management plan based on an analysis of ecological assets and maintain the typical appearance of its various types of vegetation. In the case of the Camargue Nature Reserve (France), the operational budget should be sufficient to ensure proper management. Oil prospecting and other development schemes in areas close to the Reserve should be discontinued if they constitute a risk for the Reserve's future existence.

In the Vanoise National Park (France) the building of the proposed Clou dam should be prohibited, as should the construction of ski lifts-particularly the one planned to link the resorts of Val d'Isère and Bonneval-sur-Arc. Improvements in Bonneval's economic situation should be sought only in solutions which do not jeopardize the sur- 